\title{
Plant diversity drives soil microbial biomass carbon in grasslands irrespective of global environmental change factors
}

MADHAV PRAKASH THAKUR ${ }^{1,2}$, ALEXANDRU MILCU ${ }^{3,4}$, PETE MANNING $^{5}$, PASCAL A. NIKLAUS ${ }^{6}$, CHRISTIANE ROSCHER ${ }^{7}$, SALLY POWER ${ }^{8,9}$, PETER B. REICH ${ }^{9}, 10$, STEFAN SCHEU ${ }^{11}$, DAVID TILMAN ${ }^{12}$, FUXUN AI $^{13}$, HONGYAN GUO $^{13}$, RONG JI $^{13}$, SARAH PIERCE ${ }^{8}$, NATHALY GUERRERO RAMIREZ ${ }^{1,2}$, ANNABELL NICOLA RICHTER ${ }^{14}$, KATJA STEINAUER ${ }^{1,2}$, TANJA STRECKER ${ }^{11}$, ANJA VOGEL ${ }^{14}$ and NICO EISENHAUER ${ }^{1,2}$

${ }^{1}$ German Centre for Integrative Biodiversity Research (iDiv) Halle-Jena-Leipzig, Deutscher Platz 5e, 04103 Leipzig, Germany, ${ }^{2}$ Institute of Biology, University of Leipzig, Johannisallee 21, 04103 Leipzig, Germany, ${ }^{3}$ CNRS, Ecotron - UPS 3248, Campus Baillarguet, 34980 Montferrier-sur-Lez, France, ${ }^{4}$ CNRS, Centre Centre d'Ecologie Fonctionnelle et Evolutive (CEFE, UMR-5175), 1919 Route de Mende, 34293 Montpellier, France, ${ }^{5}$ Institute of Plant Sciences, University of Bern, Altenbergrain 21, CH-3013 Bern, Switzerland, 'Institute of Evolutionary Biology and Environmental Studies, University of Zurich, Winterthurerstrasse 190, CH-8057 Zurich, Switzerland, ${ }^{7}$ UFZ, Helmholtz Centre for Environmental Research, Community Ecology, Theodor-Lieser-Strasse 4, 06120 Halle, Germany, ${ }^{8}$ Department of Life Sciences, Imperial College London, Silwood Park, Ascot Berkshire SL5 8JL, UK, ${ }^{9}$ Hawkesbury Institute for the Environment, University of Western Sydney, Locked Bag 1797, Penrith, NSW 2751, Australia, ${ }^{10}$ Department of Forest Resources, University of Minnesota, 1530 North Cleveland Avenue, St. Paul, MN 55108, USA, ${ }^{11}$ J.F. Blumenbach Institute of Zoology and Anthropology, Georg August University Göttingen, Berliner Strasse 28, Göttingen 37073, Germany, ${ }^{12}$ Department of Ecology, Evolution and Behavior, University of Minnesota, St Paul, MN 55108, USA, ${ }^{13}$ State Key Laboratory of Pollution Control and Resource Reuse, School of the Environment, Xianlin Avenue 163, 210023 Nanjing, China, ${ }^{14}$ Institute of Ecology, Friedrich Schiller University Jena, Dornburger Str. 159, 07743 Jena, Germany

\begin{abstract}
Soil microbial biomass is a key determinant of carbon dynamics in the soil. Several studies have shown that soil microbial biomass significantly increases with plant species diversity, but it remains unclear whether plant species diversity can also stabilize soil microbial biomass in a changing environment. This question is particularly relevant as many global environmental change (GEC) factors, such as drought and nutrient enrichment, have been shown to reduce soil microbial biomass. Experiments with orthogonal manipulations of plant diversity and GEC factors can provide insights whether plant diversity can attenuate such detrimental effects on soil microbial biomass. Here, we present the analysis of 12 different studies with 14 unique orthogonal plant diversity $\times$ GEC manipulations in grasslands, where plant diversity and at least one GEC factor (elevated $\mathrm{CO}_{2}$, nutrient enrichment, drought, earthworm presence, or warming) were manipulated. Our results show that higher plant diversity significantly enhances soil microbial biomass with the strongest effects in long-term field experiments. In contrast, GEC factors had inconsistent effects with only drought having a significant negative effect. Importantly, we report consistent non-significant effects for all 14 interactions between plant diversity and GEC factors, which indicates a limited potential of plant diversity to attenuate the effects of GEC factors on soil microbial biomass. We highlight that plant diversity is a major determinant of soil microbial biomass in experimental grasslands that can influence soil carbon dynamics irrespective of GEC.
\end{abstract}

Keywords: biodiversity loss, carbon dynamics, drought, long-term experiments, microbial activity, plant biomass

Received 12 March 2015 and accepted 27 May 2015

\section{Introduction}

Soil microorganisms influence many ecosystem processes related to the maintenance of soil fertility (Yao et al., 2000) and the regulation of biogeochemical cycles (Cleveland \& Liptzin, 2007; Schimel \& Schaeffer, 2012).

Correspondence: Madhav Prakash Thakur, tel. +49 34197 33172, fax +4934197 39350, e-mail: madhav.thakur@idiv.de
Moreover, the amount of soil microbial biomass carbon plays a major role in driving the balance between the release of soil carbon (respiration) and its sequestration in soil organic matter in terrestrial ecosystems (Miltner et al., 2011; Lange et al., 2015). Therefore, factors that alter the amount of soil microbial biomass are likely to change carbon dynamics in soil (Bardgett et al., 2008).

Grasslands are a major reservoir of soil carbon (Ciais et al., 2010), covering $30 \%$ of the Earth's land 
surface and storing $\sim 23 \%$ of the global terrestrial ecosystem carbon stock (Whittaker \& Likens, 1975; Trumper et al., 2009), which makes them a crucial model system to study drivers of soil microbial biomass. Some recent studies in experimental grasslands highlighted that plant diversity increases soil microbial biomass via driving inputs of organic matter and regulation of soil moisture (Zak et al., 2003; Lange et al., 2015), as diverse communities are more productive and their denser canopies cause a reduced loss of soil water (Eisenhauer et al., 2013; Vogel et al., 2013). Further, these studies showed weaker responses of soil microbial biomass to global environmental change (GEC) factors, such as $\mathrm{N}$ addition and summer drought, than to variation in plant diversity (Eisenhauer et al., 2013; Vogel et al., 2013), which parallels the response of plant biomass to plant diversity and GEC factors (Tilman et al., 2012). Although high plant diversity may provide a more stable supply of resources for soil microorganisms (Milcu et al., 2010) and could therefore buffer the destabilizing effects of other GEC factors (Zhang et al., 2005; Treseder, 2008), the aforementioned case studies found limited support for this hypothesis (Eisenhauer et al., 2013; Vogel et al., 2013). Given that GEC factors are projected to intensify in their extent and magnitude over the next decades (Vitousek et al., 1997; Field et al., 2014) and that these factors also drive biodiversity loss, a comprehensive across-study analysis is needed to explore whether negative effects of plant diversity loss on microbial biomass are exacerbated by GEC factors.

Interactive effects between plant diversity and GEC factors on microbial biomass could be manifested via a wide range of mechanisms. For instance, high diversity plant communities can retain higher soil moisture than those with low diversity (Eisenhauer et al., 2013; Lange et al., 2014), which may dampen the detrimental effects of drought or warming on soil microbial biomass through reductions in soil water content (Serna-Chavez et al., 2013). Furthermore, the different soil microbial communities that are generated by a plant diversity gradient (Zak et al., 2003; Lange et al., 2014) may respond differently to GEC factors (Bloor \& Bardgett, 2012). For instance, the autochthonous soil microbial communities that are associated with highly diverse plant communities may respond less to nutrient pulses, such as those caused by fertilization and the presence of earthworms, than the zymogenous microbial communities found with low plant diversity communities (Eisenhauer et al., 2010). Autochthonous microbial communities have higher carbon use efficiency, which implies lower soil respiration per unit of growth than zymogenous microbial communities with lower carbon use efficiency (Manzoni et al., 2012). The establishment of these more efficient autochthonous soil microbial communities in experimental high diversity plant communities takes several years (Eisenhauer et al., 2010), which makes long-term studies indispensable in the quest to understand plant diversity effects on soil microorganisms (Eisenhauer et al., 2012).

Plant diversity may also amplify the effects of GEC factors on soil microbial biomass. For instance, the effects of elevated atmospheric $\mathrm{CO}_{2}$ concentrations and $\mathrm{N}$ inputs on plant biomass production were reported to be stronger in diverse plant communities due to their higher resource use efficiency (Reich et al., 2001). As a consequence, this amplified plant biomass production can translate into greater organic matter inputs to the soil where plant diversity and elevated $\mathrm{CO}_{2}$ or $\mathrm{N}$ levels can cascade to increased soil microbial biomass (Spehn et al., 2000; Zak et al., 2003).

Recent research has highlighted that the Earth system models used to project global carbon dynamics could be improved by incorporating information on soil microbial properties, including soil microbial biomass (Wieder et al., 2013). While there is evidence that GEC factors influence soil microbial biomass (Blankinship et al., 2011; Serna-Chavez et al., 2013), and these changes are being incorporated into the new generation of Earth system models (Hurrell et al., 2013), plant diversity and its interaction with GEC factors have rarely been implemented. This gap is largely due to a lack of generalization regarding these relationships, thus warranting a synthesis of studies where plant diversity has been orthogonally crossed with other GEC factors and soil microbial biomass has been measured. Accordingly, we analyzed the data from 12 different studies comprising both field and laboratory experiments with 14 unique plant diversity $\times$ GEC factor manipulations in grassland with the aim of examining the consistency of main and interactive effects of plant diversity and GEC factors on soil microbial biomass in experimental grasslands.

\section{Materials and methods}

\section{Database}

We compiled published and unpublished data from experiments that orthogonally manipulated grassland plant diversity and at least one GEC factor. We were able to include the following GEC factors in our study: atmospheric $\mathrm{CO}_{2}$ concentrations $(n=4)$, nutrient enrichment $(n=3)$, drought $(n=3)$, earthworms $(n=3)$, and warming $(\mathrm{n}=1)$. Warming was only used in calculating two-way interaction effects from 
the mixed models (details below). All these GEC factors are recognized to strongly affect ecosystem structure and functioning (Tylianakis et al., 2008). Earthworms were included in this analysis as they represent invasive ecosystem engineers in many ecosystems with the potential to alter ecosystem structure and function (Hendrix et al., 2008), and their loss is also an important component of land-use change as many agricultural management practices reduce earthworm densities, for example, mechanical soil disturbance (Edwards \& Bohlen, 1996) and pesticide application (Pelosi et al., 2013).

All studies compiled measured soil microbial biomass carbon using an $\mathrm{O}_{2}$ microcompensation apparatus (Scheu, 1992) (Appendix S1). In total, data from 12 different experiments with 14 unique plant diversity $\times$ GEC manipulations were included in our analyses. Each study had at least three levels of plant species richness and two levels of GEC factor treatment. Among them, seven were field studies and five were experiments carried out in greenhouses or growth chambers (laboratory experiments). Soil sampled in all the studies were from the top layer of soil (5-10 cm deep), where microbial communities are most active due to high soil moisture (Griffiths et al., 2003). Details of all studies are provided in Table 1.

\section{Effect size calculation}

We calculated the natural log-response ratio as a metric of effect size for microbial biomass as $\log _{10}\left[\left(C_{\text {mic }}\right)_{\text {Trt }} /\left(C_{\text {mic }}\right)_{\text {Con }}\right]$, where $\left(C_{\text {mic }}\right)_{\text {Trt }}$ and $\left(C_{\text {mic }}\right)_{\text {Con }}$ are soil microbial biomass from treatment and control, respectively. For plant diversity effects on microbial biomass, three categories were differentiated: low, intermediate (inter), and high. This classification was performed to provide a conservative measure of the strength of plant diversity effects (Tilman et al., 2012) and to account for spatial differences in field vs. laboratory experiments. For instance, a laboratory experiment with 2 or 3 plant species per microcosm was considered equivalent to field experiments with 8 or 12 species per plot and accordingly used in the above classification scheme (see Table 1 for PSR levels used in different studies). This classification was validated by the determination of plant species richness in circular patches of $10 \mathrm{~cm}$ in diameter (to represent the diameter mostly used in microcosm laboratory experiments) in plots of the Jena Experiment (Roscher et al., 2004) with 8 and 16 plant species (eight replicates per plant diversity level). The median values of plant species per patch in 8species plots were about five, whereas in 16-species plots, it was seven species (Figure S1), which is comparable to the intermediate and high diversity levels in microcosms, respectively. Please note that the implications of this study, however, are not affected by the classification procedure as even the most conservative contrast between intermediate and high plant diversity was significant in long-term field studies (Fig. 1).

The mean log-response ratios from different studies were calculated using random effect models [restricted maximum-likelihood estimator (REML)] with 10000 boot- strapped 95\% confidence intervals (bias-corrected estimates) based on the sample variances of log-response ratio using the metafor package (Viechtbauer, 2010) for R statistical software version 3.1.0 ( $\mathrm{R}$ Development Core Team, 2014). Bootstrapping was carried out in the boot package (Canty \& Ripley, 2014). Random effect models account for the variances within and between studies and are considered appropriate when different studies included in the meta-analysis differ from each other in terms of experimental design, location, or duration (Mengersen et al., 2013). The REML estimator was used due to its balance between unbiasedness and efficiency in getting maximum-likelihood estimates from random effect models, compared to other estimators (Viechtbauer, 2005).

Further, to account for the effects of time since establishment of the plant communities on the effect of plant diversity effects on microbial biomass, we used a mixed-effect model approach with experimental duration (expressed in years) as a covariate (commonly known as moderator in the meta-analysis literature) (Viechtbauer, 2010). In all random mixed-effect models, we used study type ('laboratory' or 'field') as a random factor to account for the bias for the differences in the duration of laboratory vs. field studies. Effect size estimates were weighted for each study based on the sum of the study variance and the estimate of random-effects variance (Viechtbauer, 2010) (Table S1).

\section{Interaction effects}

We quantified plant diversity and GEC factor interaction effects in two ways. First, we used a meta-analytic approach to quantify variation in the effect size of GEC factors at their ambient and treatment levels in three plant diversity contexts: low, inter, and high. That is, plant diversity (as a linear term with three levels) was used as a covariate to explain variations in effect size of GEC factors on soil microbial biomass. This analysis was performed in the metafor package, built for R statistical software version 3.1.0.

Second, we used linear mixed models to quantify two-way interaction terms and their statistical significance for each study separately. For studies with blocks (used to account for random effects; Table 1), linear mixed-effect models were used to estimate the interaction coefficients using lme4 package (Bates et al., 2013) for R statistical software version 3.02. We further estimated $95 \%$ confidence intervals for the interaction coefficients by applying the semiparametric bootstrapping method using bootmer function in lme4 (Bates et al., 2013).

\section{Results}

We found significant positive effects of plant diversity (high vs. low plant diversity and intermediate vs. low plant diversity) on soil microbial biomass (Fig. 1). In contrast, drought was the only GEC factor that had a significant negative effect on soil microbial biomass (Fig. 1). All other effects of GEC factors on soil microbial biomass were negative; however, their effect 
Table 1 List of studies that were used for the analyses with details on the experimental setup. All these studies simultaneously manipulated plant diversity and at least one GEC factor. Full references of the published studies are provided in Appendix S2

\begin{tabular}{|c|c|c|c|c|c|}
\hline Study & $\begin{array}{l}\text { Type of } \\
\text { experiment }\end{array}$ & Location & $\begin{array}{l}\text { Levels of plant } \\
\text { diversity }\end{array}$ & $\begin{array}{l}\text { GEC } \\
\text { factors }\end{array}$ & $\begin{array}{l}\text { Levels of global } \\
\text { change agents }\end{array}$ \\
\hline Eisenhauer et al. (2012) & Laboratory & Minnesota, USA & 1,2 , and 4 & Earthworm & $\begin{array}{l}\text { Presence and absence of } \\
\text { Lumbricus terrestris }\end{array}$ \\
\hline Eisenhauer et al. (2013) & Field (B) & $\begin{array}{l}\text { BioCON Experiment, } \\
\text { Minnesota, USA }\end{array}$ & 1,4 , and 9 & $\begin{array}{l}\mathrm{CO}_{2} \text { and } \\
\text { Nutrient }\end{array}$ & $\begin{array}{l}\mathrm{CO}_{2} \text { concentration } \\
\text { (ambient and }+180 \mathrm{ppm}) ; \\
\mathrm{N} \text { concentration }(\mathrm{ambient} \\
\text { and }+4 \mathrm{~g} \mathrm{~N} \mathrm{~m}^{-2} \mathrm{yr}^{-1} \text { ) }\end{array}$ \\
\hline Ai et al. Unpubl. & Laboratory (B) & Nanjing, China & 1,2 , and $3 \dagger$ & $\mathrm{CO}_{2}$ & $\begin{array}{l}\mathrm{CO}_{2} \text { concentration } \\
\text { (ambient and }+200 \mathrm{ppm})\end{array}$ \\
\hline Milcu et al. (2006) & Laboratory & $\begin{array}{l}\text { Darmstadt, } \\
\text { Germany }\end{array}$ & 1,4 , and 8 & Earthworm & $\begin{array}{l}\text { Presence and absence of } \\
\text { two earthworm species } \\
\text { (Lumbricus terrestris and } \\
\text { Aporrectodea caliginosa) }\end{array}$ \\
\hline Milcu et al. (2011) & Laboratory (B) & $\begin{array}{l}\text { Silwood Park, } \\
\text { Ascot, UK }\end{array}$ & 1,4 , and 8 & $\begin{array}{l}\mathrm{CO}_{2} \text { and } \\
\text { Earthworm }\end{array}$ & $\begin{array}{l}\mathrm{CO}_{2} \text { concentration } \\
\text { (ambient }=400 \mathrm{ppm} \text { and } \\
\text { elevated }=600 \mathrm{ppm}) ; \\
\text { earthworm (presence and } \\
\text { absence of Lumbricus } \\
\text { terrestris) }\end{array}$ \\
\hline Niklaus et al. (2007) & Field (B) & $\begin{array}{l}\text { Northwestern } \\
\text { Switzerland }\end{array}$ & 5,12 , and 31 & $\mathrm{CO}_{2}$ & $\begin{array}{l}\mathrm{CO}_{2} \text { concentration } \\
(\text { ambient }=356 \mathrm{ppm} \text { and } \\
\text { elevated }=600 \mathrm{ppm})\end{array}$ \\
\hline Ramirez et al. Unpubl. & Laboratory & Jena, Germany & 1,2 , and 4 & Drought & $\begin{array}{l}50 \% \text { reduction in water in } \\
\text { drought treatments } \\
\text { compared to controls }\end{array}$ \\
\hline Roscher et al. Unpubl. & Field (B) & $\begin{array}{l}\text { Bad Lauchstädt, } \\
\text { Germany }\end{array}$ & 1,2 , and 4 & Nutrient & $\begin{array}{l}\text { Ambient and }+\mathrm{NPK} \\
\text { fertilizer as } 120: 52: 100 \\
\left(\mathrm{~kg} \mathrm{ha}^{-1} \mathrm{yr}^{-1}\right) \\
\left(\mathrm{N} \text { as } \mathrm{NO}_{3}-\mathrm{N} / \mathrm{NH}_{4}-\mathrm{N}\right. \\
\text { equal proportions, } \\
\left.\mathrm{P} \text { as } \mathrm{P}_{2} \mathrm{O}_{5}-\mathrm{P}, \mathrm{K} \text { as } \mathrm{K}_{2} \mathrm{O}-\mathrm{K}\right)\end{array}$ \\
\hline Steinauer et al. (2015) & Field (B) & $\begin{array}{l}\text { BAC Experiment, } \\
\text { Minnesota, USA }\end{array}$ & 1,4 , and 16 & Warming & $\begin{array}{l}\text { Temperature (ambient, }+ \\
1.5 \text {, and }+3^{\circ} \mathrm{C} \text { ) }\end{array}$ \\
\hline Strecker et al. (2015) & Field (B) & $\begin{array}{l}\text { Jena Experiment, } \\
\text { Jena, Germany }\end{array}$ & 1,8 , and 16 & Nutrient & $\begin{array}{l}\text { Ambient and }+\mathrm{NPK} \\
\text { fertilizer as } 100: 43.6: \\
83\left(\mathrm{~kg} \mathrm{ha}^{-1} \mathrm{yr}^{-1}\right) \\
\left(\mathrm{N} \text { as } \mathrm{NO}_{3}-\mathrm{N} / \mathrm{NH}_{4}-\mathrm{N} \text { equal }\right. \\
\text { proportions, } \mathrm{P} \text { as } \mathrm{P}_{2} \mathrm{O}_{5}-\mathrm{P}, \mathrm{K} \text { as } \\
\left.\mathrm{K}_{2} \mathrm{O}-\mathrm{K}\right)\end{array}$ \\
\hline Thakur et al. Unpubl.* & Field (B) & $\begin{array}{l}\text { DIRECT, Silwood Park, } \\
\text { UK }\end{array}$ & 1,2 , and $3 \dagger$ & Drought & $\begin{array}{l}\text { Rainfall manipulation } \\
\text { (ambient vs. }-30 \% \text { in summer) }\end{array}$ \\
\hline Vogel et al. (2012) & Field (B) & $\begin{array}{l}\text { Jena Experiment, } \\
\text { Jena, Germany }\end{array}$ & 1,8, and 16 & Drought & $\begin{array}{l}\text { Ambient rainfall and drought } \\
\text { manipulation using roof } \\
(-53.7 \mathrm{~mm} \text { rainfall })\end{array}$ \\
\hline
\end{tabular}

B, block design.

${ }^{*}$ Experimental design details are provided in Fry et al. (2013).

$\dagger$ Functional diversity.

size was not significantly different from zero (95\% CI overlapping with zero; Fig. 1). Plant diversity did not explain the variations in effect size of any GEC factor on soil microbial biomass (Fig. 2). These results were supported by insignificant interaction effects among all 14 two-way interactions tested between plant diversity and GEC factors (Table 2). Further, few GEC factors showed a significant effect on microbial biomass (three 


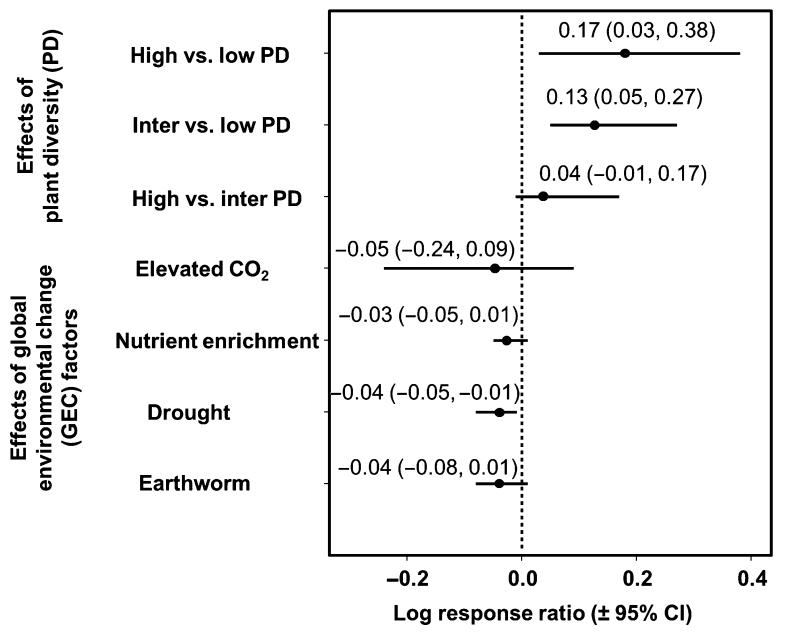

Fig. 1 Effect sizes (mean log-response ratio) of plant diversity and GEC factors on soil microbial biomass with bootstrapped 95\% confidence intervals (CI). Effect sizes are significant only when confidence intervals do not overlap with zero. The values inside the brackets next to effect size values are low $(2.5 \%)$ and high $(97.5 \%)$ confidence intervals. The details of effect size and confidence intervals of GEC factors are provided in Table S3. in total), all of them causing a decline, compared to consistently stronger and positive (except one negative out of five significant effects) effects of plant diversity, when studies were analyzed separately (Table S2).

We found plant diversity effects on soil microbial biomass were most pronounced in long-term field studies (Fig. 3). Plant diversity effects were greater in high vs. low and inter vs. low contrasts as compared to high vs. intermediate plant diversity contrasts. Large variability in effect sizes (grater size of confidence intervals) was common in short-term laboratory studies (Fig. 3). Further, when time since establishment of plant communities was used as a covariate, we found that it explained a significant fraction of the variance in effect size and was positively correlated with the effect size for high vs. low plant diversity comparisons (slope $=0.07,2.5 \% \quad \mathrm{CI}=0.06,97.5 \% \mathrm{CI}=0.08$ ). We found similar results for the variations in effect sizes of inter vs. low plant diversity (slope $=0.04,2.5 \%$ $\mathrm{CI}=0.03,97.5 \% \mathrm{CI}=0.05)$ and high vs. intermediate plant diversity (slope $=0.02,2.5 \% \quad \mathrm{CI}=0.01,97.5 \%$ $\mathrm{CI}=0.03)$ (Fig. 4).
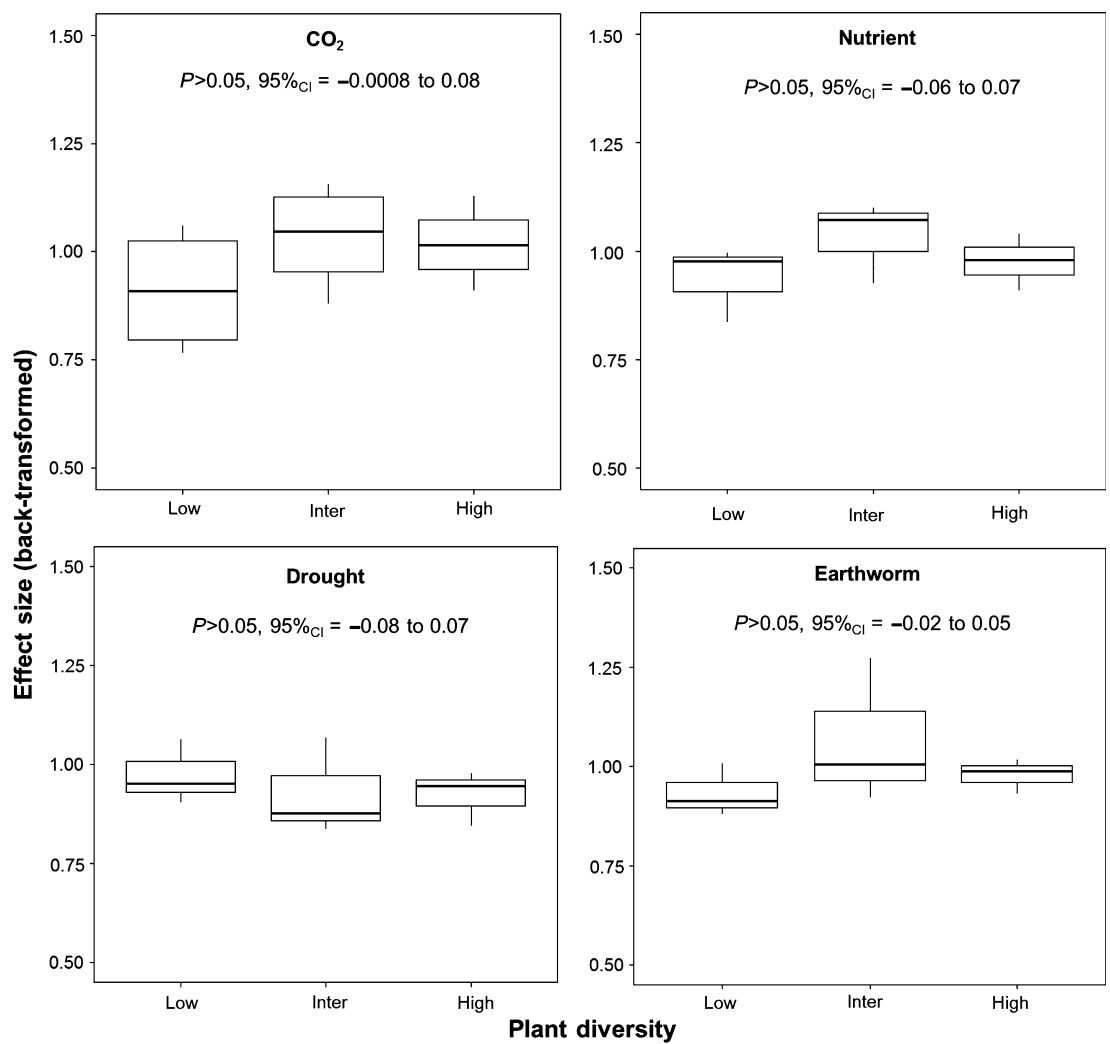

Fig. 2 Effects of GEC factors on microbial biomass at three levels of plant diversity (Effect sizes are reported as backtransformed logresponse ratio). The statistics shown in the figure are calculated using plant diversity as a covariate to explain variations in effect sizes of the GEC factors shown in the figure. 
Table 2 Bootstrapped coefficient of interaction terms from the linear mixed models for interactions between plant diversity and GEC factors on microbial biomass (log-transformed). Confidence intervals (CI) are 95\% percentile bootstrapped. Slopes and their significance for the main effects (plant diversity and GEC factors) from the mixed-effect models are provided in Table S1

\begin{tabular}{|c|c|c|c|c|c|}
\hline Study & Interaction terms & Slope & Low CI $(2.5 \%)$ & High CI $(97.5 \%)$ & $P$-value \\
\hline Eisenhauer et al. (2012) & Plant diversity $\times$ Earthworm & -0.0398 & -0.1318 & 0.0834 & 0.49 \\
\hline Eisenhauer et al. (2013) & Plant diversity $\times \mathrm{CO}_{2}$ & 0.0270 & -0.0142 & 0.0695 & 0.19 \\
\hline Eisenhauer et al. (2013) & Plant diversity $\times$ Nutrient & -0.0030 & -0.0450 & 0.0390 & 0.88 \\
\hline Ai et al. Unpubl. & Plant diversity (functional) $\times \mathrm{CO}_{2}$ & 0.0889 & -0.0432 & 0.2226 & 0.18 \\
\hline Milcu et al. (2006) & Plant diversity $\times$ Earthworm & 0.0029 & -0.0122 & 0.0191 & 0.39 \\
\hline Milcu et al. (2011) & Plant diversity $\times$ Earthworm & -0.0050 & -0.0239 & 0.0135 & 0.56 \\
\hline Milcu et al. (2011) & Plant diversity $\times \mathrm{CO}_{2}$ & 0.0060 & -0.0121 & 0.0256 & 0.54 \\
\hline Niklaus et al. (2003) & Plant diversity $\times \mathrm{CO}_{2}$ & -0.0145 & -0.0658 & 0.0388 & 0.53 \\
\hline Ramirez et al. Unpubl. & Plant diversity $\times$ Drought & 0.0769 & -0.0829 & 0.2598 & 0.36 \\
\hline Roscher et al. Unpubl. & Plant diversity $\times$ Nutrient & -0.0017 & -0.0511 & 0.0492 & 0.97 \\
\hline Steinauer et al. (2015) & Plant diversity $\times$ Warming & 0.0006 & -0.0124 & 0.0136 & 0.68 \\
\hline Strecker et al. (2015) & Plant diversity $\times$ Nutrient & 0.0075 & -0.0052 & 0.0211 & 0.23 \\
\hline Thakur et al. Unpubl. & Plant diversity (functional) $\times$ Drought & -0.0210 & -0.1704 & 0.1317 & 0.77 \\
\hline Vogel et al. (2013) & Plant diversity $\times$ Drought & 0.0001 & -0.0105 & 0.0116 & 0.95 \\
\hline
\end{tabular}

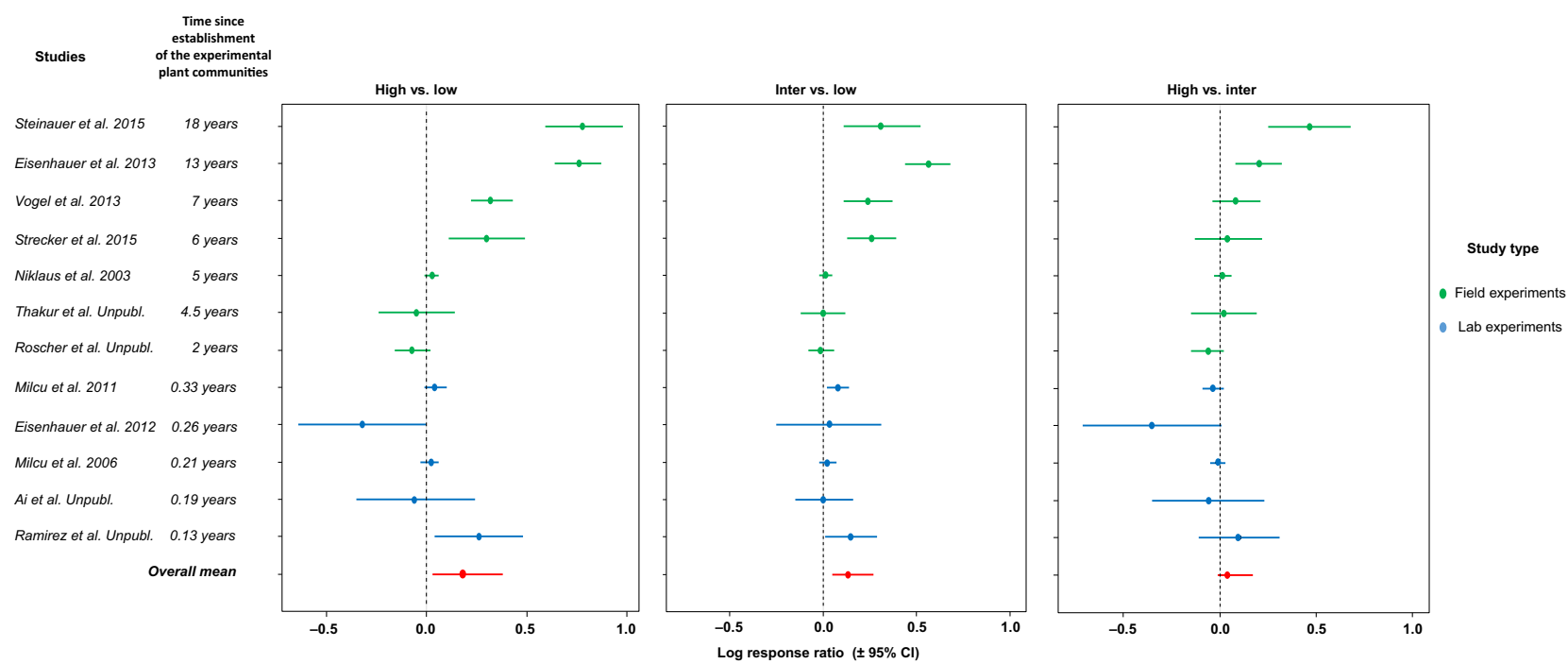

Fig. 3 Effect size (log-response ratio) of plant diversity effects on soil microbial biomass with $95 \%$ confidence intervals for 12 studies categorized as field and laboratory experiments. Studies are ordered in terms of their study duration from longer to shorter (given in years). The overall effect size in red color resembles the one provided in figure 1 for plant diversity effects. The details of effect size and confidence intervals are available in Table S4.

\section{Discussion}

Our results provide the first quantitative across-study evidence for strong plant diversity effects on soil microbial biomass in long-term field experiments, but also shows that plant diversity has a limited capacity to attenuate the effects of other GEC factors. Notably, we did not detect a single significant interaction effect between plant diversity and other GEC factors on soil microbial biomass (Fig. 2, Table 2), indicating that long-term plant diversity effects are strong but invari- ant across global change contexts. Further, we observed a greater positive effect size of plant diversity effects on soil microbial biomass than effects of elevated atmospheric $\mathrm{CO}_{2}$ concentrations, nutrient enrichment, drought, and earthworms from grassland experiments with orthogonal manipulations of plant diversity and GEC factors (Fig. 1).

The strong and positive plant diversity effects on soil microbial biomass could be due to several non-mutually exclusive mechanisms. First, a study comparing the sizes of the effects of various GEC factors on net 

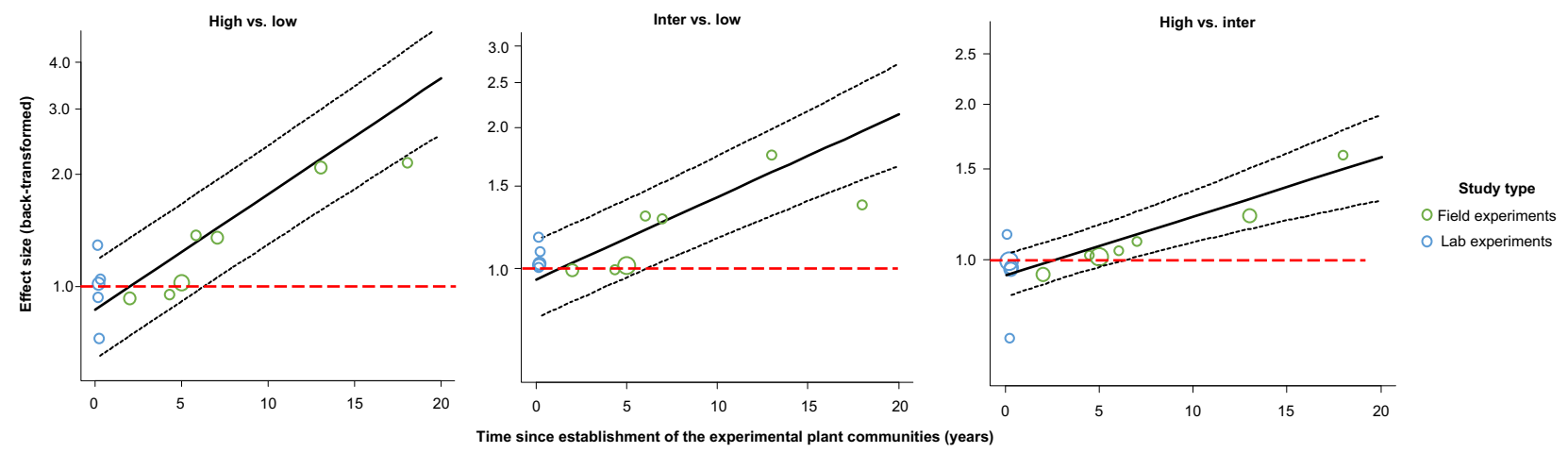

Fig. 4 Relation between the time since establishment of the plant community and the effect sizes of plant diversity on soil microbial biomass (back-transformed by taking exponentials of log-response ratio) from 12 studies. The dashed lines are $\pm 95 \%$ confidence intervals. The thick red line indicates an effect size of 1 , that is, neutral plant diversity effect on soil microbial biomass. The size of the circles indicates the approximate weight of the study from the mixed-effect model. Exact weights for each studies are provided in Table S1.

primary productivity found that experimental manipulations of plant biodiversity had as great or greater an impact on net primary productivity as nitrogen addition and had greater effect sizes than elevated $\mathrm{CO}_{2}$, fire, herbivory, and drought or water addition (Tilman et al., 2012). As microbial biomass should increase with plant productivity within a given region (Zak et al., 2003), the greater effect size of plant species diversity on plant productivity could contribute to the responses of microbial biomass that we observed. To test this hypothesis, we explored whether the positive relation between aboveground productivity and soil microbial biomass holds true in studies with a stronger plant diversity effect on soil microbial biomass (Fig. 3). Indeed, we found a positive association between aboveground productivity and microbial biomass with negligible effects of GEC factors modifying this relationship (Fig. S2).

Second, microbial biomass could be regulated via direct relationships between plant roots and microbial growth (Grayston \& Wang, 1998; Bever et al., 2012), along with indirect effects of plant diversity on soil microhabitat conditions, such as soil temperature (Spehn et al., 2000) or moisture (Eisenhauer et al., 2013). Diverse plant communities have been shown to fuel microbial growth in soil more than low diversity plant communities (Hooper et al., 2000; Stephan et al., 2000), and this may be due to higher amounts of rhizodeposits (Knops et al., 2002; Lange et al., 2015). Moreover, diverse plant communities are expected to have higher phylogenetic and root trait diversity, and this may in turn result in the exudation of a more diverse range of organic compounds into their rhizosphere, which can sustain higher microbial biomass (Hooper et al., 2000). Positive plant diversity effects could also be mediated via changes in soil physio-chemical factors particularly via soil moisture - a key abiotic factor regulating soil microbial biomass (Wardle, 1992) - that has been shown to positively correlate with high plant diversity in the topsoil (Eisenhauer et al., 2013; Lange et al., 2014).

Global environmental change factors can affect soil microbial biomass by altering resource availability in the soil. For instance, a meta-analysis showed that $\mathrm{N}$ enrichment decreased soil microbial biomass across ecosystems by inhibiting microbial growth and activity, mostly by reducing fungal biomass (Treseder, 2008). Another recent meta-analysis also found that $\mathrm{N}$ enrichment detrimentally affects soil microbial biomass due to a net decline in carbon acquisition by plant roots at high nitrogen availability, which in turn reduces carbon availability for soil microorganisms (Janssens et al., 2010). Our study also showed an overall negative effect (although not significant) of nutrient enrichment on soil microbial biomass; thus, our results are in line with Treseder (2008) and Janssens et al. (2010). However, as our study focused on orthogonal manipulations of plant diversity and GEC drivers, we had lower replication than these other studies.

Studies in North American grasslands reported that elevated $\mathrm{CO}_{2}$ and $\mathrm{N}$ enrichment only marginally increased plant biomass production when compared to the effect size of plant species richness (Reich et al., 2001), with limited potential to have any cascading effect on soil microbial biomass (Eisenhauer et al., 2013). We speculate that weak GEC effects on soil microbial biomass might have been possibly due to relatively minor alterations of carbon availability in the soil by GEC factors in our analysis. This could also be true for the varying strength of plant diversity effects on microbial biomass in the studies considered; that is, plant diversity effects on soil microbial biomass were only significant in cases where plant diversity also 
increased soil carbon concentrations (Eisenhauer et al., 2010). In addition, recent studies have shown that soil moisture and plant-derived organic matter inputs controlled soil microbial biomass and activities (Lange et al., 2014, 2015).

Our results on drought showed a negative effect on soil microbial biomass, which is consistent with the idea that soil moisture is an important regulator of soil microbial communities (Wardle, 1992; Serna-Chavez et al., 2013). Drought can affect microbial physiology even in the short term, while population and community level responses, which would be manifested in the microbial biomass, can be less pronounced (Schimel et al., 2007). This could explain the relatively weak effect of drought on microbial biomass (all drought studies ran for <2 years). Further, the drought treatments were typically applied for short periods of only weeks to months, while variations in plant diversity may influence soil moisture over longer periods of time, for example, throughout the whole growing season.

The effects of GEC factors on soil microbial biomass could also depend on how strongly they influence biotic interactions between soil microbial communities and plants (Rouifed et al., 2010; Bloor \& Bardgett, 2012). GEC factors, such as drought, could intensify competition for nutrients between soil microorganisms and plants, if the microbial communities are poorly adapted to tolerate drought (Bloor \& Bardgett, 2012), and diverse plant communities may be more efficient in their nutrient uptake (Hooper \& Vitousek, 1998). Such a situation could cause an interactive effect between plant diversity and drought on microbial biomass (Bloor \& Bardgett, 2012). The lack of interaction between GEC factors and plant diversity in our study indicates that microbial communities in high diversity plant communities were probably adapted to the manipulated GEC factors. However, this speculation needs further experimental investigation. Some GEC factors, such as drought, could also shift soil microbial community composition, for example, by altering the balance between aerobic and anaerobic microbial biomass (Fenner \& Freeman, 2011). The latter is not represented by the substrate-induced respiration method used in the studies that entered our analysis, and so, it is possible that such changes went undetected. Future studies are required to investigate possible functional shifts in soil microbial communities in response to plant diversity and GEC factors and the implications of this for microbial biomass and soil carbon turnover.

Time since plant community establishment plays a crucial role for the effect of plant diversity on microbial biomass, with plant diversity effects often only becoming significant after a time lag of several years (Eisenhauer et al., 2010). This implies that positive associations between soil microbial biomass and diverse plant communities need time to develop due to the slow accumulation of plant-derived carbon resources in the soil over time (Eisenhauer et al., 2012; Kuzyakov \& $\mathrm{Xu}$, 2013). Additionally, root exudation, a major resource for soil microorganisms, peaks in grassland diversity experiments after several growing seasons (Harris, 2009). Species-rich plant communities increase complementary resource use with time (Cardinale et al., 2007), and this subsequently increases plant diversity effects on both shoot and root biomass (Reich et al., 2012). Increases in shoot and root biomass, in turn, provide higher resource availability for soil microorganisms, which is likely to increase soil microbial biomass (Spehn et al., 2000; Zak et al., 2000).

Our study highlights the importance of plant diversity as a key driver of soil microbial biomass, with particularly strong effects in long-term field experiments. As those long-term studies provide a more realistic picture of the significance of plant diversity effects (Eisenhauer et al., 2012; Reich et al., 2012), we expect changes in plant diversity to have important implications for soil carbon dynamics (Lange et al., 2015). Although caution must be taken when transferring results of plant diversity experiments to relationships in natural communities, there is some evidence that relationships between plant diversity and soil microbial biomass also are significantly positive in plant removal experiments (Wardle et al., 1999) and in natural plant diversity gradients (Eisenhauer et al., 2011), thus implying that our results have significant implications for local changes in plant diversity in natural settings. As biodiversity is projected to decline in response to GEC factors (Isbell et al., 2013), we also expect indirect effects of GEC on soil microbial biomass via alterations in plant diversity. Although plant diversity may not buffer effects of other GEC factors, it needs to be maintained to maximize soil microbial biomass, due to its importance in the regulation of soil functions, including soil carbon sequestration.

\section{Acknowledgements}

We would like to thank Julia Koricheva and Dylan Craven for providing suggestions on the data analyses. MPT and NE acknowledge funding by the German Research Foundation (DFG) in the frame of the Emmy Noether research group (Ei 862/2) and the German Centre for Integrative Biodiversity Research (iDiv) Halle-Jena-Leipzig, funded by the German Research Foundation (FZT 118). Bad Lauchstädt Experiment acknowledges the funding by the DFG (RO2397/4). The Jena Experiment is funded by the DFG (FOR 1451) with additional support from the Max Planck Society and the University of Jena. 


\section{References}

Bardgett RD, Freeman C, Ostle NJ (2008) Microbial contributions to climate change through carbon cycle feedbacks. The ISME Journal, 2, 805-814.

Bates D, Maechler M, Bolker BM, Walker S (2013) Lme4: Linear Mixed-Effects Models Using S4 Classes. R package version 1.3-11, http://cran.r-project.org/web/ packages/lme4/index.html (accessed 11 February 2015).

Bever JD, Platt TG, Morton ER (2012) Microbial population and community dynamics on plant roots and their feedbacks on plant communities. Annual Review of Microbiology, 66, 265-283.

Blankinship JC, Niklaus PA, Hungate BA (2011) A meta-analysis of responses of soil biota to global change. Oecologia, 165, 553-565.

Bloor JMG, Bardgett RD (2012) Stability of above-ground and below-ground processes to extreme drought in model grassland ecosystems: Interactions with plant species diversity and soil nitrogen availability. Perspectives in Plant Ecology, Evolution and Systematics, 14, 193-204.

Canty A, Ripley B (2014) Boot: Bootstrap R (S-Plus) Functions. R Package version 1.311, http://cran.r-project.org/web/packages/boot/index.html (accessed 11 February 2015).

Cardinale BJ, Wright JP, Cadotte MW et al. (2007) Impacts of plant diversity on biomass production increase through time because of species complementarity. Proceedings of the National Academy of Sciences of the United States of America, 104, 18123-18128.

Ciais P, Soussana JF, Vuichard N et al. (2010) The greenhouse gas balance of European grasslands. Biogeosciences Discussions, 7, 5997-6050.

Cleveland CC, Liptzin D (2007) C:N: P stoichiometry in soil: is there a "Redfield ratio" for the microbial biomass? Biogeochemistry, 85, 235-252.

Edwards CA, Bohlen PJ (1996) Biology and Ecology of Earthworms (3rd edn). Chapman \& Hall, London.

Eisenhauer N, Bessler H, Engels C et al. (2010) Plant diversity effects on soil microorganisms support the singular hypothesis. Ecology, 91, 485-496.

Eisenhauer N, Yee K, Johnson E, Maraun M, Parkinson D, Straube D, Scheu S (2011) Positive relationship between herbaceous layer diversity and the performance of soil biota in a temperate forest. Soil Biology and Biochemistry, 43, 462-465.

Eisenhauer N, Reich PB, Scheu S (2012) Increasing plant diversity effects on productivity with time due to delayed soil biota effects on plants. Basic and Applied Ecology, 13, 571-578.

Eisenhauer N, Dobies T, Cesarz S, Hobbie SE, Meyer RJ, Worm K, Reich PB (2013) Plant diversity effects on soil food webs are stronger than those of elevated $\mathrm{CO}_{2}$ and $\mathrm{N}$ deposition in a long-term grassland experiment. Proceedings of the National Academy of Sciences of the United States of America, 110, 6889-6994.

Fenner N, Freeman C (2011) Drought-induced carbon loss in peatlands. Nature Geoscience, 4, 895-900

Field CB, Barros VR, Mach KJ et al. (2014) Technical summary. In: Climate Change 2014: Impacts, Adaptation, and Vulnerability. Part A: Global and Sectoral Aspects. Contribution of Working Group II to the Fifth Assessment Report of the Intergovernmental Panel on Climate Change (eds Field CB, Barros VR, Dokken DJ, Mach KJ, Mastrandrea MD, Bilir TE, Chatterjee M, Ebi KL, Estrada YO, Genova RC, Girma B, Kissel ES, Levy AN, MacCracken S, Mastrandrea PR, White LL), pp. 35-94. Cambridge University Press, Cambridge, UK and New York, NY, USA

Fry EL, Manning P, Allen DGP, Hurst A, Everwand G, Rimmler M, Power SA (2013) Plant Functional Group Composition Modifies the Effects of Precipitation Change on Grassland Ecosystem Function. PLoS ONE, 8, e57027.

Grayston S, Wang S (1998) Selective influence of plant species on microbial diversity in the rhizosphere. Soil Biology and Biochemistry, 30, 369-378.

Griffiths R, Whiteley A, O'Donnell AG, Bailey M (2003) Influence of depth and sampling time on bacterial community structure in an upland grassland soil. FEMS Microbiology Ecology, 43, 35-43.

Harris J (2009) Soil microbial communities and restoration ecology: facilitators or followers? Science, 325, 573-574.

Hendrix PF, Callaham MA, Drake JM, Huang C-Y, James SW, Snyder BA, Zhang W (2008) Pandora's box contained bait: the global problem of introduced earthworms * Annual Review of Ecology, Evolution, and Systematics, 39, 593-613.

Hooper D, Vitousek P (1998) Effects of plant composition and diversity on nutrient cycling. Ecological Monographs, 68, 121-149.

Hooper DU, Bignell DE, Brown VK et al. (2000) Interactions between aboveground and belowground biodiversity in terrestrial ecosystems: patterns, mechanisms, and feedbacks. BioScience, 50, 1049-1061.

Hurrell JW, Holland MM, Gent PR et al. (2013) The community earth system model: a framework for collaborative research. Bulletin of the American Meteorological Society, 94, 1339-1360.
Isbell F, Reich PB, Tilman D, Hobbie SE, Polasky S, Binder S (2013) Nutrient enrichment, biodiversity loss, and consequent declines in ecosystem productivity. Proceedings of the National Academy of Sciences of the United States of America, 110, 11911-11916.

Janssens IA, Dieleman W, Luyssaert S et al. (2010) Reduction of forest soil respiration in response to nitrogen deposition. Nature Geoscience, 3, 315-322.

Knops J, Bradley K, Wedin D (2002) Mechanisms of plant species impacts on ecosystem nitrogen cycling. Ecology Letters, 5, 454-466.

Kuzyakov Y, Xu X (2013) Competition between roots and microorganisms for nitrogen: mechanisms and ecological relevance. New Phytologist, 198, 656-669.

Lange M, Habekost M, Eisenhauer N et al. (2014) Biotic and abiotic properties mediating plant diversity effects on soil microbial communities in an experimental grassland. PLOS ONE, 9, e96182.

Lange M, Eisenhauer N, Sierra C et al. (2015) Plant diversity drives soil carbon storage by increased soil microbial activity. Nature Communications, 6, 6707.

Manzoni S, Taylor P, Richter A, Porporato A, Agren GI (2012) Environmental and stoichiometric controls on microbial carbon-use efficiency in soils. The New Phytologist, 196, 79-91.

Mengersen K, Schmid C, Jennions M, Gurevitch J (2013) Statistical models and approaches to inference. In: Handbook of Meta-Analysis in Ecology and Evolution (eds Koricheva J, Gurevitch J, Mengersen K), pp. 89-107. Princeton University Press, New Jersey, USA.

Milcu A, Thebault E, Scheu S, Eisenhauer N (2010) Plant diversity enhances the reliability of belowground processes. Soil Biology and Biochemistry, 42, 2102-2110.

Miltner A, Bombach P, Schmidt-Brücken B, Kästner M (2011) SOM genesis: microbial biomass as a significant source. Biogeochemistry, 111, 41-55.

Pelosi C, Barot S, Capowiez Y, Hedde M, Vandenbulcke F (2013) Pesticides and earthworms. A review. Agronomy for Sustainable Development, 34, 199-228.

R Core Team (2014) R: A Language and Environment for Statistical Computing. R Foundation for Statistical Computing, Vienna, Austria.

Reich PB, Knops J, Tilman D et al. (2001) Plant diversity enhances ecosystem responses to elevated $\mathrm{CO}_{2}$ and nitrogen deposition. Nature, 411, 809-812.

Reich PB, Tilman D, Isbell F, Mueller K, Hobbie SE, Flynn DFB, Eisenhauer N (2012) Impacts of biodiversity loss escalate through time as redundancy fades. Science, 336, 589-592.

Roscher C, Schumacher J, Baade J (2004) The role of biodiversity for element cycling and trophic interactions: an experimental approach in a grassland community. $\mathrm{Ba}$ sic and Applied Ecology, 121, 107-121

Rouifed S, Handa IT, David J-F, Hättenschwiler S (2010) The importance of biotic factors in predicting global change effects on decomposition of temperate forest leaf litter. Oecologia, 163, 247-256.

Scheu S (1992) Automated measurement of the respiratory response of soil microcompartments: active microbial biomass in earthworm faeces. Soil Biology and Biochemistry, 24, 1-6.

Schimel JP, Schaeffer SM (2012) Microbial control over carbon cycling in soil. Frontier in Microbiology, 3, 1-11.

Schimel J, Balser T, Wallenstein M (2007) Microbial stress-response physiology and its implications for ecosystem function. Ecology, 88, 1386-1394.

Serna-Chavez HM, Fierer N, van Bodegom PM (2013) Global drivers and patterns of microbial abundance in soil. Global Ecology and Biogeography, 22, 1162-1172.

Spehn E, Joshi J, Schmid B, Alphei J, Körner C (2000) Plant diversity effects on soil heterotrophic activity in experimental grassland ecosystems. Plant and Soil, 224, 217-230.

Stephan A, Meyer A, Schmid B (2000) Plant diversity affects culturable soil bacteria in experimental grassland communities. Journal of Ecology, 88, 988-998.

Tilman D, Reich PPB, Isbell F (2012) Biodiversity impacts ecosystem productivity as much as resources, disturbance, or herbivory. Proceedings of the National Academy of Science of the United States of America, 109, 10394-10397.

Treseder KK (2008) Nitrogen additions and microbial biomass: a meta-analysis of ecosystem studies. Ecology Letters, 11, 1111-1120.

Trumper K, Bertzky B, Dickson M, van der Heijden MGA, Jenkins M, Manning P (2009) The Natural fix?. The role of ecosystems in climate mitigation, Cambridge, UK, United Nations Environment Programme.

Tylianakis JM, Didham RK, Bascompte J, Wardle DA (2008) Global change and species interactions in terrestrial ecosystems. Ecology Letters, 11, 1351-1363.

Viechtbauer W (2005) Bias and efficiency of meta-analytic variance estimators in the random-effects model. Journal of Educational and Behavioral Statistics, 30, 261293.

Viechtbauer W (2010) Conducting meta-analyses in R with the metafor package. Journal of Statistical Software, 36, 1-48.

Vitousek PM, Mooney HA, Lubchenco J, Melillo JM (1997) Human domination of Earth's ecosystems. Science, 277, 494-499. 
Vogel A, Eisenhauer N, Weigelt A, Scherer-Lorenzen M (2013) Plant diversity does not buffer drought effects on early-stage litter mass loss rates and microbial properties. Global Change Biology, 19, 2795-2803.

Wardle D (1992) A comparative assessment of factors which influence microbial biomass carbon and nitrogen levels in soil. Biological Review, 67, 321-358.

Wardle DA, Bonner KI, Barker GM et al. (1999) Plant removals in Perennial Grassland : vegetation dynamics, decomposers, soil biodiversity, and ecosystem properties. Ecological Monographs, 69, 535-568.

Whittaker R, Likens E (1975) The Biosphere and Man. In: Primary Productivity of the Biosphere, Ecological Studies No. 14 (eds Lieth H, Whittaker R), p. 306. Springer-Verlag, Berlin.

Wieder WR, Bonan GB, Allison SD (2013) Global soil carbon projections are improved by modelling microbial processes. Nature Climate Change, $3,1-4$
Yao H, He Z, Wilson M, Campbell C (2000) Microbial biomass and community structure in a sequence of soils with increasing fertility and changing land use. Microbial Ecology, 40, 223-237.

Zak DR, Pregitzer K, King J, Holmes W (2000) Elevated atmospheric $\mathrm{CO}_{2}$, fine roots and the response of soil microorganisms: a review and hypothesis. New Phytologist, 147, 201-222.

Zak DR, Holmes WE, White DC, Peacock AD, Tilman D (2003) Plant diversity, soil microbial communities, and ecosystem function: are there any links? Ecology, 84, 2042-2050.

Zhang W, Parker KM, Luo Y, Wan S, Wallace LL, Hu S (2005) Soil microbial responses to experimental warming and clipping in a tallgrass prairie. Global Change Biology, 11, 266-277.

\section{Supporting Information}

Additional Supporting Information may be found in the online version of this article:

Appendix S1. Microbial biomass measurement using $\mathrm{O}_{2}$ device.

Figure S1. Plant species richness within $10 \mathrm{~cm}$ diameter from 8 - and 16 - species mixture plots of the Jena Experiment.

Table S1. Weight of the studies from the random mixed-effect model (duration of plant community establishment as a covariate, see methods) for high vs. low, inter vs. low and high vs. inter plant diversity effect size calculation.

Table S2. Slopes for the main effects of plant diversity and global environmental change (GEC) factors on microbial biomass carbon (log-transformed) from the linear mixed and mixed-effect (those with a randomized block design) models (two-way interactions) from 12 studies. Significant slopes (p-value $<0.05$ ) are given in bold.

Figure S2. Relation between plant shoot biomass and soil microbial biomass shown for three global environmental change factors in low, intermediate, and high plant diversity.

Table S3. Effect size (log response ratio) and confidence intervals (CI) of global environmental change (GEC) factors on soil microbial biomass carbon.

Table S4. Effect size (log response ratio) and confidence intervals (CI) of plant diversity effects on soil microbial biomass carbon for three diversity effect comparisons (high vs. low, intermediate vs. low, and high vs. intermediate).

Appendix S2. References. 